\title{
Total Syntheses of (+)-1893B and Its Three Diastereomers and Evaluation of Their Biological Activities
}

\author{
Hiroyuki Yasui, Kunihiro Hirai, Shun Yamamoto, Ken-ichi Takao, Kin-ichi Tadano
}

This paper is dedicated to the memory of Professor Kenneth L. Rinehart.

Received: May 18, 2006 / Accepted: July 28, 2006

(C) Japan Antibiotics Research Association

\begin{abstract}
The total syntheses of natural (+)-1893B (2) and three other diastereomers 14, 18, and 21 were accomplished. Starting from the sequential metathesis product 5 prepared in turn from a 7-oxanorbornene derivative (+)-4, 2 was synthesized by means of an epoxyring opening of $9 \mathrm{a}$ with trimethylsilylacetylide followed by Wacker-type oxidation of the resulting alkyne $\mathbf{1 0}$ for the construction of the $\gamma$-lactone moiety. By applying the same synthetic sequence, three additional diastereomers of $\mathbf{2 , 1 4}$, 18, and 21 were also synthesized. The biological activities of previously synthesized 1893A (1), 1893B (2), and the diastereomers of 1893B 14, 18, and 21 were investigated.
\end{abstract}

Keywords (+)-1893B, total synthesis, oxabicyclo[4.2.1]nona-2,4-diene, $\gamma$-lactone

\section{Introduction}

1893A (1) and 1893B (2) were isolated in 2003 during the course of antitumor natural products searching from a marine endophytic fungus designated as No. 1893, which exists in mangroves (Fig. 1) [1]. Lin and Chen reported that the extract mixture of No. 1893 appeared to exhibit cytotoxic and insecticidal activities. However, the biological activity of the pure metabolites $\mathbf{1}$ and $\mathbf{2}$ has not reported. The structure of $\mathbf{1}$ was elucidated by extensive spectroscopic studies and finally determined by X-ray

K. Tadano (Corresponding author), H. Yasui, K. Hirai, S. Yamamoto, K. Takao: Department of Applied Chemistry, Keio University, Hiyoshi, Kohoku-ku, Yokohama 223-8522, Japan, E-mail: tadano@applc.keio.ac.jp crystallographic analysis. As structurally related natural product, (+)-mycoepoxydiene (3) was isolated in 1999 $[2,3]$. We already reported the total syntheses of $\mathbf{1}$ and 3 , which were characterized by a sequential ringopening/cross/ring-closing metathesis strategy [4, 5]. Although the stereostructures of $\mathbf{1}$ and $\mathbf{3}$ were confirmed by our synthetic studies, the stereochemistry of $\mathbf{2}$ was not unambiguously established at that time. Later, we were concerned with the stereochemically defined total synthesis of 2 through the total syntheses of all four possible stereoisomers regarding the vicinal diol moiety in $\mathbf{2}$. The first total synthesis of natural $(+)-2$ was reported as a preliminary communication [6]. Herein, we describe in detail the total syntheses of $\mathbf{2}$ and three additional diastereomers. The evaluation of their biological activities is also presented.

\section{Results and Discussion}

According to our previous report [5], we converted the enantioenriched 7-oxanorbornene derivative (+)-4 $(>95 \%$ ee) into the cyclooctadiene $\mathbf{5}$ through a one-pot ring-expansion metathesis strategy (Scheme 1). The

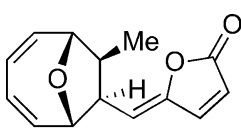

$(-)-1893 A(1)$

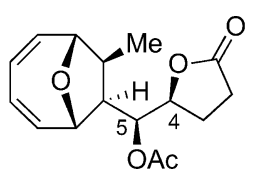

(+)-1893B (2)

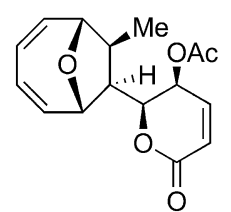

(+)-mycoepoxydiene (3)
Fig. 1 Structures of 1893s and mycoepoxydiene. 


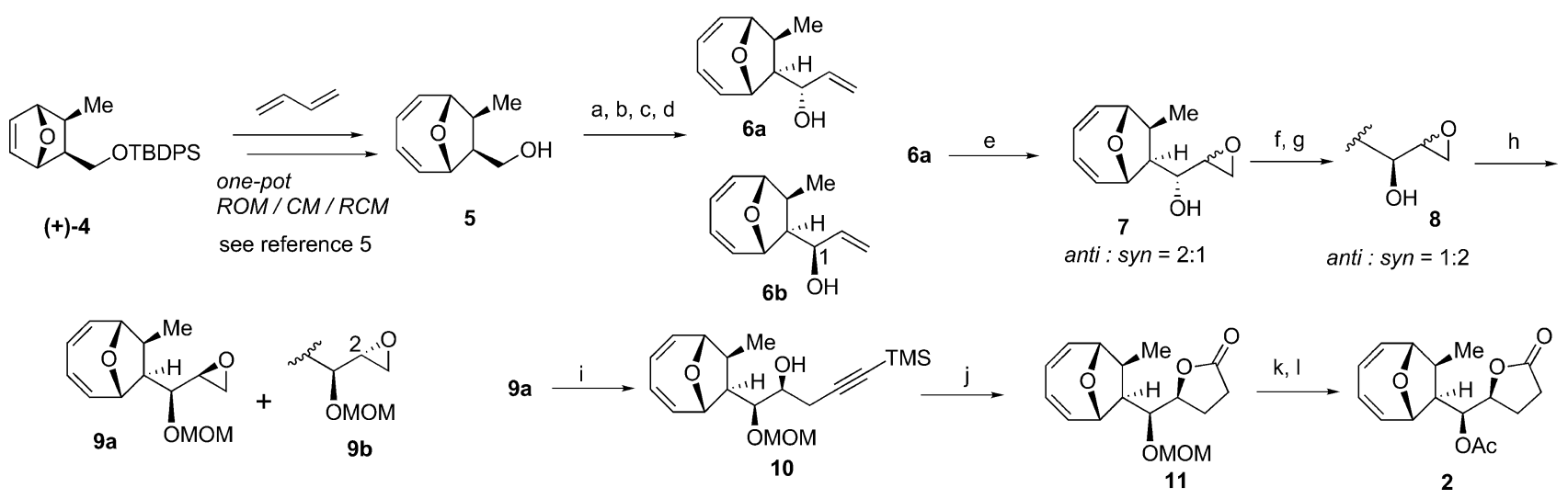

Scheme 1 Total synthesis of natural (+)-2.

Reagents and conditions: (a) Dess-Martin periodinane, $\mathrm{CH}_{2} \mathrm{Cl}_{2}$; (b) $\mathrm{CH}_{2}=\mathrm{CHMgBr}$, THF, 70\% for 2 steps; (c) (S)-O-acetylmandelic acid, $\mathrm{EDCl} \cdot \mathrm{HCl}, \mathrm{DMAP}, \mathrm{CH}_{2} \mathrm{Cl}_{2}$; (d) $\mathrm{LiOH}, \mathrm{MeOH} / \mathrm{H}_{2} \mathrm{O}, 40 \%$ of $\mathbf{6 a}$ for 2 steps, $52 \%$ for $\mathbf{6 b}$; (e) $\mathrm{VO}(\mathrm{acac}) 2, t-\mathrm{BuOOH}_{2} \mathrm{CH}_{2} \mathrm{Cl}_{2}, 60 \%$; (f) $\mathrm{PPh}$, DEAD, p-nitrobenzoic acid, THF; (g) LiOH, MeOH/ $\mathrm{H}_{2} \mathrm{O}, 84 \%$ for 2 steps; (h) MOMCl, $i-\mathrm{Pr}_{2} \mathrm{NEt}, \mathrm{DMAP}, \mathrm{CH}_{2} \mathrm{Cl}_{2}$, reflux, 54\% for 9a, 35\% for 9b; (i) TMS-acetylene, $n$-BuLi, $\mathrm{BF}_{3} \cdot \mathrm{Et}_{2} \mathrm{O}, \mathrm{THF},-78$ to $-30^{\circ} \mathrm{C}, 99 \%$; (j) $\mathrm{PdCl}_{2}\left(\mathrm{MeCN}_{2}, \mathrm{CuCl}_{2}, \mathrm{DMF}\right.$ containing $1 \%$ water, $71 \%$; (k) $2 \mathrm{M} \mathrm{HCl}, \mathrm{THF}$, $50^{\circ} \mathrm{C}, 98 \%$; (I) $\mathrm{Ac}_{2} \mathrm{O}$, DMAP, pyridine, $84 \%$.

primary alcohol in this cascade metathesis product $\mathbf{5}$ was oxidized to an aldehyde, which was then reacted with vinylmagnesium bromide, affording diastereomeric allylic alcohols $\mathbf{6 a}$ and $\mathbf{6 b}$ as an inseparable $1: 1$ mixture. To establish the stereochemistry of the diatereomers $\mathbf{6 a}$ and $\mathbf{6 b}$, the mixture was esterified with $(S)$ - $O$-acetylmandelic acid. The resulting two mandelic esters were cleanly separated by chromatography on silica-gel. After removal of the mandeloyl group from each ester, diastereomerically pure 6a and $\mathbf{6 b}$ were obtained. The newly introduced stereocenter of C-1 in $\mathbf{6 b}$ was determined as depicted using the $\Delta \delta$ values of the $(S)$ - and $(R)$-mandelic esters derived from $\mathbf{6 b}$ in their ${ }^{1} \mathrm{H}-\mathrm{NMR}$ spectra [7]. The stereochemically defined allylic alcohol 6a was subjected to the Sharpless $\mathrm{VO}(\mathrm{acac})_{2}$-catalyzed epoxidation [8], affording epoxy alcohols 7 as a 2:1 diastereomeric mixture. We deduced from the Sharpless empirical rule that the major isomer was anti-epoxy alcohol unsuitable for the synthesis of $\mathbf{2}$. Thus the Mitsunobu inversion of the diastereomeric mixture 7 was carried out using $p$ nitrobenzoic acid [9]. As expected, the anti:syn ratio turned from $2: 1$ to $1: 2$. The resulting $p$-nitrobenzoates were hydrolyzed to epoxy alcohols $\mathbf{8}$ as the $s y n$-enriched form. After protection of the hydroxyl groups, syn- and anti-epoxy MOM ethers $9 \mathbf{a}$ and $\mathbf{9 b}$ were cleanly separated. The stereochemistry at $\mathbf{C}-2$ of $\mathbf{9 b}$ was unambiguously established based on the ${ }^{1} \mathrm{H}$ NMR difference $(\Delta \delta)$ of the corresponding $(S)$ - and $(R)$ - $O$-acetylmandeloyl esters prepared from $9 \mathbf{b}$ by regioselective hydride opening of the epoxy ring followed by esterification [7]. The opening of the epoxy ring of 9a with a two-carbon nucleophile was investigated. After several attempts, we found that lithium trimethylsilylacetylide efficiently provided the desired product 10. For an introduction of the $\gamma$-lactone part, 10 was subjected to a Wacker-oxidation-like reaction using a palladium catalyst, providing the desired lactone 11. This oxidative cyclization was considered to proceed via regioselective trans-hydroxypalladations followed by [PdCl/TMS] syn-elimination [10]. After deprotection of $\mathbf{1 1}$ followed by acetylation, (+)-1893B (2) was obtained. The spectroscopic data (IR, ${ }^{1} \mathrm{H}-$ and ${ }^{13} \mathrm{C}-\mathrm{NMR}, \mathrm{HRMS},[\alpha]_{\mathrm{D}}$ ) of synthetic 2 were identical with those reported for natural (+)-1893B in all respects.

Furthermore, we synthesized three diastereomers of $\mathbf{2}$, i.e., 14, 18 and 21, from the stereochemically defined intermediates 6a (for $\mathbf{1 8}$ and 21) or $\mathbf{9 b}$ (for 14) via exactly the same synthetic routes used for the conversion of $\mathbf{6 a}$ to 2 (Scheme 2).

\section{Biological Activities of 1893 Series}

Finally, the biological activities of (+)-1983 A (1) and $(+)-1983 \mathrm{~B}(\mathbf{2})$ and the three stereoisomers 14, 18, and 21 were explored (Table 1). Compound $\mathbf{1}$ was found to exhibit weak cytotoxicity in vitro against human chronic myelogenous leukemia K562 and human hepatocellular carcinoma HepG2 cells. However, neither compounds $\mathbf{2}$, nor diastereomers 14, 18, and 21 showed either antibacterial activities against a variety of Gram-positive and Gramnegative bacteria and cytotoxicity against the two tumor cell lines. 

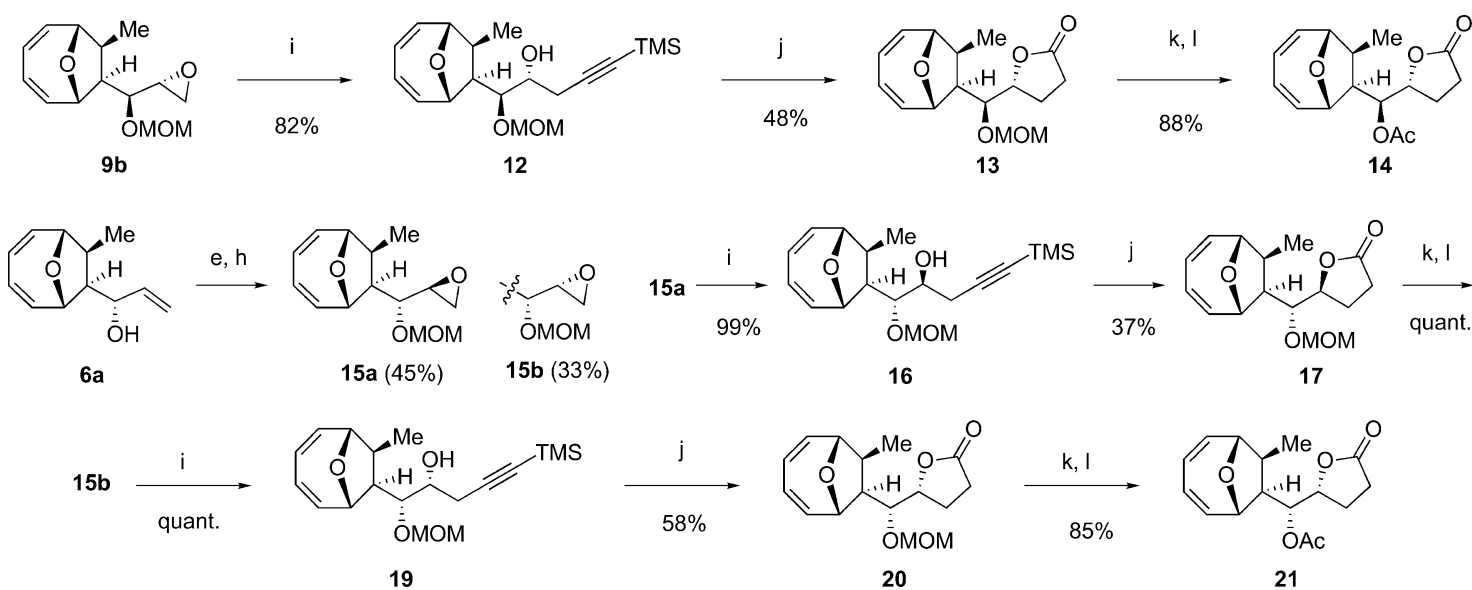

Scheme 2 Syntheses of other diastereomers 14, 18 and $\mathbf{2 1 .}$

Reagents and conditions: The same reaction conditions as described in Scheme 1 were used.

Table 1 Biological activities of 1893 series

\begin{tabular}{|c|c|c|c|c|c|}
\hline K562 cells & \multicolumn{5}{|c|}{$\mathrm{IC}_{50}(\mu \mathrm{g} / \mathrm{ml})$} \\
\hline batch & 1893A (1) & 1893B (2) & 14 & 18 & 21 \\
\hline $1 s t$ & 26 & $>64$ & $>64$ & $>64$ & $>64$ \\
\hline 2nd & 19 & $>64$ & $>64$ & $>64$ & $>64$ \\
\hline Ave. & 23 & $>64$ & $>64$ & $>64$ & $>64$ \\
\hline HepG2 cells & \multicolumn{5}{|c|}{$\mathrm{IC}_{50}(\mu \mathrm{g} / \mathrm{ml})$} \\
\hline batch & 1893A (1) & 1893B (2) & 14 & 18 & 21 \\
\hline $1 s t$ & 26 & $>64$ & $>64$ & $>64$ & $>64$ \\
\hline 2nd & 21 & $>64$ & $>64$ & $>64$ & $>64$ \\
\hline Ave. & 23 & $>64$ & $>64$ & $>64$ & $>64$ \\
\hline
\end{tabular}

\section{Experimental}

Melting points are uncorrected. Specific rotations were measured in a $10 \mathrm{~mm}$ cell. ${ }^{1} \mathrm{H}-\mathrm{NMR}$ spectra were recorded at JEOL GSX-270 $(270 \mathrm{MHz})$ and ${ }^{13} \mathrm{C}$ NMR spectra at JEOL GSX-270 $(68 \mathrm{~Hz})$. All spectra were recorded in $\mathrm{CDCl}_{3}$. High-resolution mass spectra were measured by JEOL JMS-GCMATE spectrometer. Thin-layer chromatography (TLC) was performed with a glass plate coated with Kieselgel $60 \mathrm{~F}_{254}$ (Merck). The crude reaction mixtures and extractive materials were purified by chromatography on silica gel Silica Gel 60 (Merck) or Wakogel C300 (Wako Pure Chemical Industries). Unless otherwise described, reactions were carried out at ambient temperature.
Combined organic extracts were dried over anhydrous $\mathrm{Na}_{2} \mathrm{SO}_{4}$. Commercially available solvents were dried (drying reagent in brackets) and distilled prior to use: $N$, $N$-dimethylformamide (DMF) $\left[\mathrm{CaH}_{2}\right], \mathrm{CH}_{2} \mathrm{Cl}_{2}\left[\mathrm{CaH}_{2}\right]$, benzene $\left[\mathrm{CaH}_{2}\right]$, and pyridine $[\mathrm{NaOH}]$.

\section{Preparation of Diastereomeric Mixture of Allylic Alcohols 6a and 6b}

The following reaction was carried out under Ar. To a cooled $\left(0^{\circ} \mathrm{C}\right)$ stirred solution of crude aldehyde $(65.5 \mathrm{mg}$, $370 \mu \mathrm{mol})$ in THF $(1 \mathrm{ml})$, prepared from enantioenriched 5 ( $>95 \%$ ee) by Dess-Martin oxidation according to the previous report [5], was added vinylmagnesium bromide $(1.0 \mathrm{M}$ solution in THF, $0.6 \mathrm{ml}, 0.6 \mathrm{mmol})$. After being stirred for 10 minutes at $0^{\circ} \mathrm{C}$, the solution was quenched with saturated aqueous $\mathrm{NH}_{4} \mathrm{Cl}(1 \mathrm{ml})$, diluted with saturated aqueous $\mathrm{NH}_{4} \mathrm{Cl}(10 \mathrm{ml})$, and extracted with $\mathrm{CH}_{2} \mathrm{Cl}_{2}(5 \mathrm{ml} \times 4)$. The combined extracts were dried and concentrated in vacuo. The residue was purified by column chromatography on silica gel (EtOAc/hexane, $1: 4$ ), providing $49.5 \mathrm{mg}(70 \%)$ of the inseparable mixture of $\mathbf{6 a}$ and $\mathbf{6 b}$ as a colorless oil.

\section{Separation of Allylic Alcohols 6a and $6 \mathrm{~b}$}

To a cooled $\left(0^{\circ} \mathrm{C}\right)$ stirred solution of the mixture of 6a and $6 \mathbf{b}(49.4 \mathrm{mg}, 257 \mu \mathrm{mol})$ in $\mathrm{CH}_{2} \mathrm{Cl}_{2}(2 \mathrm{ml})$ were added $(S)-(+)-O$-acetylmandelic acid $(200 \mathrm{mg}, 1.03 \mathrm{mmol})$, $\mathrm{EDCI} \cdot \mathrm{HCl}(197 \mathrm{mg}, 1.03 \mathrm{mmol})$, and 4-DMAP $(12.6 \mathrm{mg}$, $103 \mu \mathrm{mol})$. The mixture was stirred for 10 minutes at $0^{\circ} \mathrm{C}$, diluted with EtOAc $(10 \mathrm{ml})$, and washed with $1 \mathrm{M}$ aqueous $\mathrm{HCl}(5 \mathrm{ml} \times 3)$, saturated aqueous $\mathrm{NaHCO}_{3}$ $(5 \mathrm{ml} \times 3)$, then $\mathrm{H}_{2} \mathrm{O}(5 \mathrm{ml})$. The organic layer was dried and concentrated in vacuo. The residue was purified by column 
chromatography on silica gel (EtOAc/toluene, $1: 80$ ) to provide $47.0 \mathrm{mg}(53 \%)$ of $(1 R)$-ester derived from $\mathbf{6 b}$ and $36.3 \mathrm{mg}(41 \%)$ of $(1 S)$-ester derived from 6a. The $(1 R)$-ester was isoleted as a colorless oil: TLC Rf 0.17 (EtOAc/toluene, 1:15); $[\alpha]_{\mathrm{D}}^{21.5}+58.2\left(c\right.$ 1.1, $\mathrm{CHCl}_{3}$ ); IR (neat) 2940, $1750 \mathrm{~cm}^{-1}$; ${ }^{1} \mathrm{H}$ NMR $\delta 1.00(\mathrm{~d}, 3 \mathrm{H}$, $J=6.6 \mathrm{~Hz}), 2.19(\mathrm{~s}, 3 \mathrm{H}), 2.72(\mathrm{~m}, 1 \mathrm{H}), 2.80(\mathrm{~m}, 1 \mathrm{H}), 4.26$ (d, $1 \mathrm{H}, J=4.4 \mathrm{~Hz}), 4.28$ (d, $1 \mathrm{H}, J=5.5 \mathrm{~Hz}), 5.10$ (dd, $1 \mathrm{H}$, $J=0.9,10.2 \mathrm{~Hz}), 5.13(\mathrm{dd}, 1 \mathrm{H}, J=0.9,17.2 \mathrm{~Hz}), 5.21$ (dd, $1 \mathrm{H}, J=7.4,10.4 \mathrm{~Hz}$ ), 5.49 (ddd, $1 \mathrm{H}, J=7.4,10.2,17.2 \mathrm{~Hz}$ ), $5.85(\mathrm{~s}, 1 \mathrm{H}), 5.82 \sim 5.91(\mathrm{~m}, 2 \mathrm{H}), 6.02 \sim 6.11(\mathrm{~m}, 2 \mathrm{H})$, $7.33 \sim 7.52(\mathrm{~m}, 5 \mathrm{H}) ;{ }^{13} \mathrm{C}$ NMR $\delta 14.1,20.6,52.4,55.5$, 74.6, 75.5, 77.6, 86.8, 119.2, 124.5, 125.7, 127.7, 128.7, $129.3, \quad 135.1 \times 2, \quad 137.6 \times 2, \quad 138.6 \times 2, \quad 167.7, \quad 170.4$; EIHRMS calcd for $\mathrm{C}_{22} \mathrm{H}_{24} \mathrm{O}_{5}\left(\mathrm{M}^{+}\right) \mathrm{m} / z$ 368.1624, found 368.1625. The (1S)-ester was isoleted as white crystals: $\mathrm{mp}$ 125.2 $127.0^{\circ} \mathrm{C}$; TLC Rf 0.19 (EtOAc/toluene, $1: 15$ ); $[\alpha]_{\mathrm{D}}^{23.5}+110\left(c\right.$ 0.97, $\left.\mathrm{CHCl}_{3}\right)$; IR ( $\mathrm{KBr}$ disk) 2940, $1745 \mathrm{~cm}^{-1}$; ${ }^{1} \mathrm{H}$ NMR $\delta 0.92(\mathrm{~d}, 1 \mathrm{H}, J=7.0 \mathrm{~Hz}), 2.19$ (s, $3 \mathrm{H}), 2.55 \sim 2.62(\mathrm{~m}, 2 \mathrm{H}), 3.99(\mathrm{t}, 1 \mathrm{H}, J=5.3 \mathrm{~Hz}), 4.11(\mathrm{~d}$, $1 \mathrm{H}, J=4.8 \mathrm{~Hz}), 5.23(\mathrm{~m}, 1 \mathrm{H}), 5.28(\mathrm{~d}, 1 \mathrm{H}, J=10.7 \mathrm{~Hz})$, $5.42(\mathrm{~d}, 1 \mathrm{H}, J=17.2 \mathrm{~Hz}), 5.62(\mathrm{dd}, 1 \mathrm{H}, J=6.8,10.7 \mathrm{~Hz})$, $5.70 \sim 5.86(\mathrm{~m}, 2 \mathrm{H}), 5.90(\mathrm{~s}, 1 \mathrm{H}), 5.90 \sim 5.97(\mathrm{~m}, 2 \mathrm{H})$, $7.21 \sim 7.40(\mathrm{~m}, 5 \mathrm{H}) ;{ }^{13} \mathrm{C}-\mathrm{NMR} \delta 14.3,20.7,52.0,54.8$, 74.6, 75.9, 78.8, 86.4, 119.2, 124.6, 124.7, 128.1, 128.9, $129.6,133.6,134.4,136.7 \times 2,139.0 \times 2,167.9,170.3$; EIHRMS calcd for $\mathrm{C}_{22} \mathrm{H}_{24} \mathrm{O}_{5}\left(\mathrm{M}^{+}\right) \mathrm{m} / z$ 368.1624, found 368.1623 .

To a cooled $\left(0^{\circ} \mathrm{C}\right)$ stirred solution of the $(1 S)$-ester (30.0 mg, $81.4 \mu \mathrm{mol})$ in $\mathrm{H}_{2} \mathrm{O} / \mathrm{MeOH}(1: 1, \mathrm{v} / \mathrm{v}, 1 \mathrm{ml})$ was added $\mathrm{LiOH} \cdot \mathrm{H}_{2} \mathrm{O}(17.1 \mathrm{mg}, 407 \mu \mathrm{mol})$. The mixture was stirred for 3 hours, diluted with saturated brine $(10 \mathrm{ml})$, and extracted with $\mathrm{CH}_{2} \mathrm{Cl}_{2}(5 \mathrm{ml} \times 3)$. The combined extracts were dried and concentrated in vacuo. The residue was purified by column chromatography on silica gel (EtOAc/ hexane, $1: 4)$ to provide $15.3 \mathrm{mg}(98 \%)$ of $\mathbf{6 a}$ as a colorless oil: TLC Rf 0.57 (EtOAc/hexane, $1: 1) ;[\alpha]_{D}^{20.0}+12.1(c$ $1.27, \mathrm{CHCl}_{3}$ ); IR (neat) $3420,2950 \mathrm{~cm}^{-1} ;{ }^{1} \mathrm{H}$ NMR $\delta 1.16$ (d, $3 \mathrm{H}, J=7.0 \mathrm{~Hz}$ ), 2.26 (br m, $1 \mathrm{H}), 2.53$ (dt, $1 \mathrm{H}, J=4.3$, $7.0 \mathrm{~Hz}), 2.66(\mathrm{~m}, 1 \mathrm{H}), 4.16(\mathrm{~m}, 1 \mathrm{H}), 4.26(\mathrm{dd}, 1 \mathrm{H}, J=2.9$, $5.1 \mathrm{~Hz}), 4.72(\mathrm{t}, 1 \mathrm{H}, J=4.3 \mathrm{~Hz}), 5.20(\mathrm{td}, 1 \mathrm{H}, J=1.5$, $10.6 \mathrm{~Hz}), 5.37(\mathrm{td}, 1 \mathrm{H}, J=1.5,16.9 \mathrm{~Hz}), 5.82 \sim 5.94(\mathrm{~m}$, $3 \mathrm{H}), 6.09 \sim 6.17(\mathrm{~m}, 2 \mathrm{H}) ;{ }^{13} \mathrm{C} \mathrm{NMR} \delta 14.0,49.6,60.1$, 72.2, 80.0, 85.7, 115.6, 124.9, 125.1, 137.4, 138.5, 140.2; EIHRMS calcd for $\mathrm{C}_{12} \mathrm{H}_{16} \mathrm{O}_{2}\left(\mathrm{M}^{+}\right) \mathrm{m} / z$ 192.1150, found 192.1163.

Analogously, 6b was obtained from the $(1 R)$-ester in $52 \%$ yield for tow steps: TLC Rf 0.57 (EtOAc/hexane, $1: 1) ;[\alpha]_{\mathrm{D}}^{25.0}+125\left(c \mathrm{1} .83, \mathrm{CHCl}_{3}\right)$; IR (KBr disk) 3420, $2940 \mathrm{~cm}^{-1} ;{ }^{1} \mathrm{H}$ NMR $\delta 1.15$ (d, $\left.3 \mathrm{H}, J=7.0 \mathrm{~Hz}\right), 1.56$ (br s, $1 \mathrm{H}), 2.53(\mathrm{ddd}, 1 \mathrm{H}, J=3.3,6.6,10.3 \mathrm{~Hz}), 2.83(\mathrm{~m}, 1 \mathrm{H})$, $4.10(\mathrm{~m}, 1 \mathrm{H}), 4.21 \sim 4.28(\mathrm{~m}, 2 \mathrm{H}), 5.16$ (ddd, $1 \mathrm{H}, J=0.7$, $1.5,11.4 \mathrm{~Hz}), 5.29(\mathrm{td}, 1 \mathrm{H}, J=1.5,17.2 \mathrm{~Hz}), 5.76 \sim 5.89(\mathrm{~m}$, $3 \mathrm{H}), 6.01 \sim 6.15(\mathrm{~m}, 2 \mathrm{H}) ;{ }^{13} \mathrm{C}$ NMR $\delta 14.2,52.7,57.9$, 73.0, 78.0, 86.8, 116.2, 124.4, 125.5, 137.4, 138.9, 141.1; EIHRMS calcd for $\mathrm{C}_{12} \mathrm{H}_{16} \mathrm{O}_{2}\left(\mathrm{M}^{+}\right) \mathrm{m} / z$ 192.1150, found 192.1169.

\section{VO(acac) $)_{2}$-catalyzed Epoxidation of 6a. Preparation of Diatereomeric Mixture of Epoxy-alcohols 7}

To a cooled $\left(0^{\circ} \mathrm{C}\right)$ stirred solution of $\mathbf{6 a}(79.8 \mathrm{mg}$, $415 \mu \mathrm{mol})$ in $\mathrm{CH}_{2} \mathrm{Cl}_{2}(1.5 \mathrm{ml})$ were added $\mathrm{VO}(\mathrm{acac})_{2}$ (20.8 mM solution in $\mathrm{CH}_{2} \mathrm{Cl}_{2}, 1.0 \mathrm{ml}, 20.8 \mu \mathrm{mol}$ ) and $t$ $\mathrm{BuO}_{2} \mathrm{H}(5.53 \mathrm{M}$ solution in isooctane, $0.22 \mathrm{ml}, 1.25 \mathrm{mmol})$. The mixture was stirred for 3 hours, diluted with EtOAc $(10 \mathrm{ml})$, and washed with saturated aqueous $\mathrm{Na}_{2} \mathrm{SO}_{3}(5 \mathrm{ml} \times 3)$, saturated aqueous $\mathrm{NaHCO}_{3}(5 \mathrm{ml})$, and saturated brine $(5 \mathrm{ml})$. The organic layer was dried and concentrated in vacuo. The residue was purified by column chromatography on silica gel (EtOAc/hexane, $1: 2)$ to provide $51.9 \mathrm{mg}(60 \%)$ of the $2: 1$ mixture of anti- and syn-epoxy alcohols 7 as a colorless oil: TLC, Rf 0.49 (EtOAc/hexane, $3: 2$ ); IR (neat) 3430, $2940 \mathrm{~cm}^{-1} ;{ }^{1} \mathrm{H}$ NMR for the major anti-isomer $\delta 1.16(\mathrm{~d}, 3 \mathrm{H}, J=7.0 \mathrm{~Hz}), 2.41$ (brd, $1 \mathrm{H}, J=3.2 \mathrm{~Hz}), 2.54(\mathrm{td}, 1 \mathrm{H}, J=4.5,6.9 \mathrm{~Hz}$ ), $2.74 \sim 2.81(\mathrm{~m}, 3 \mathrm{H}), 3.05$ (ddd, $1 \mathrm{H}, J=3.3,3.8,4.3 \mathrm{~Hz}$ ), 3.81 (ddd, $1 \mathrm{H}, J=3.2,3.3,6.9 \mathrm{~Hz}$ ), 4.27 (dd, $1 \mathrm{H}, J=2.4$, $4.9 \mathrm{~Hz}), 4.78$ (dd, $1 \mathrm{H}, J=3.8,4.9 \mathrm{~Hz}), 5.85 \sim 5.92(\mathrm{~m}, 2 \mathrm{H})$, $6.01 \sim 6.23(\mathrm{~m}, 2 \mathrm{H}) ;{ }^{13} \mathrm{C}$ NMR for the major anti-isomer $\delta$ $14.6,43.9,50.4,53.8,56.5,68.6,79.4,85.8,125.1 \times 2$, 137.2, 138.5; EIHRMS calcd for $\mathrm{C}_{12} \mathrm{H}_{16} \mathrm{O}_{3}\left(\mathrm{M}^{+}\right) \mathrm{m} / \mathrm{z}$ 208.1099, found 208.1088 .

\section{Mitsunobu Inversion of the Diastereomeric Mixture 7. Preparation of the $1: 2$ Mixture of anti- and syn-Epoxy- alcolols 8}

To a cooled $\left(0^{\circ} \mathrm{C}\right)$ stirred solution of the inseparable mixture of epoxy-alcohols 7 (7.9 mg, $38 \mu \mathrm{mol}), \mathrm{PPh}_{3}$ $(40.0 \mathrm{mg}, 152 \mu \mathrm{mol})$, and 4-nitrobenzoic acid $(25.9 \mathrm{mg}$, $155 \mu \mathrm{mol})$ in THF $(1.0 \mathrm{ml})$ was added dropwise diethyl azodicarboxylate $(73 \mu \mathrm{l}, 0.16 \mathrm{mmol})$. After being stirred for 5 hours, the solution was diluted with $1 \mathrm{M}$ aqueous $\mathrm{HCl}$ $(5 \mathrm{ml})$ and extracted with EtOAc $(3 \times 10 \mathrm{ml})$. The combined extracts were dried and concentrated in vacuo. The residue was purified by column chromatography on silica gel (EtOAc/hexane, $1: 5$ ) to provide $18.6 \mathrm{mg}$ of mixture of the 4-nitrobenzoate esters.

To a cooled $\left(0^{\circ} \mathrm{C}\right)$ stirred solution of thus obtained mixture $(18.6 \mathrm{mg})$ in $\mathrm{H}_{2} \mathrm{O} / \mathrm{MeOH},(1: 1, \mathrm{v} / \mathrm{v}, 1 \mathrm{ml})$ was added $\mathrm{LiOH} \cdot \mathrm{H}_{2} \mathrm{O}(7.9 \mathrm{mg}, 0.19 \mathrm{mmol})$. This was stirred for 4 hours, diluted with saturated brine $(10 \mathrm{ml})$, and extracted with $\mathrm{CH}_{2} \mathrm{Cl}_{2}(5 \mathrm{ml} \times 3)$. The combined extracts were dried 
and concentrated in vacuo. The residue was purified by column chromatography on silica gel (EtOAc/hexane, $1: 2$ ) to provide $6.6 \mathrm{mg}$ ( $84 \%$ for 2 steps) of the $1: 2$ mixture of anti- and syn-epoxy alcohols $\mathbf{8}$ as a colorless oil: TLC, Rf 0.49 (EtOAc/hexane, $3: 2$ ); IR (neat) $3425,2940 \mathrm{~cm}^{-1} ;{ }^{1} \mathrm{H}$ NMR for the major $s y n$-isomer $\delta 1.13(\mathrm{~d}, 3 \mathrm{H}, J=7.0 \mathrm{~Hz})$, 1.95 (br d, $1 \mathrm{H}, J=5.4 \mathrm{~Hz}$ ), 2.61 (td, $1 \mathrm{H}, J=6.6,10.7 \mathrm{~Hz}$ ), $2.80 \sim 2.98(\mathrm{~m}, 4 \mathrm{H}), 3.45(\mathrm{td}, 1 \mathrm{H}, J=5.4,10.7 \mathrm{~Hz}), 4.28(\mathrm{~d}$, $1 \mathrm{H}, J=4.4 \mathrm{~Hz}), 4.34$ (t, $1 \mathrm{H}, J=6.0 \mathrm{~Hz}), 5.86 \sim 5.95(\mathrm{~m}, 2 \mathrm{H})$, $6.09,6.22(2 \mathrm{~m}$, each $1 \mathrm{H}) ;{ }^{13} \mathrm{C} \mathrm{NMR}$ for the major synisomer $\delta 14.1,45.9,53.3,55.3,62.3,70.9,77.3,86.2$, 124.5, 126.3, 137.6, 137.8; EIHRMS calcd for $\mathrm{C}_{12} \mathrm{H}_{16} \mathrm{O}_{3}$ $\left(\mathrm{M}^{+}\right) \mathrm{m} / z$ 208.1099, found 208.1088.

\section{Preparation of Separable MOM Ethers 9a and 9b}

To a stirred solution of $\mathbf{8}(21.9 \mathrm{mg}, 105 \mu \mathrm{mol})$ in $\mathrm{CH}_{2} \mathrm{Cl}_{2}(1 \mathrm{ml})$ were added $i$-Pr $2 \mathrm{NEt}(259 \mu \mathrm{l}, 1.05 \mathrm{mmol})$, chloromethyl methyl ether $(41 \mu 1,0.53 \mathrm{mmol})$, and 4 DMAP $(6.4 \mathrm{mg}, 53 \mu \mathrm{mol})$. The mixture was refluxed for 24 hours, diluted with saturated aqueous $\mathrm{NaHCO}_{3}(10 \mathrm{ml})$, and extracted with $\mathrm{CH}_{2} \mathrm{Cl}_{2}(5 \mathrm{ml} \times 3)$. The combined extracts were dried and concentrated in vacuo. The residue was purified by column chromatography on silica gel (EtOAc/hexane, 1:4) to provide $14.4 \mathrm{mg}$ (54\%) of 9a and $9.1 \mathrm{mg}(35 \%)$ of $\mathbf{9 b}$. Compound $9 \mathbf{a}$ was isolated as a colorless oil: TLC Rf 0.43 (EtOAc/hexane, $3: 2$ ); $[\alpha]_{\mathrm{D}}^{21.5}$ +25.4 (c $0.25, \mathrm{CHCl}_{3}$ ); IR (neat) $2930 \mathrm{~cm}^{-1} ;{ }^{1} \mathrm{H}$ NMR $\delta$ $1.10(\mathrm{~d}, 3 \mathrm{H}, J=7.0 \mathrm{~Hz}), 2.62 \sim 2.71(\mathrm{~m}, 2 \mathrm{H}), 2.81 \sim 2.90(\mathrm{~m}$, $2 \mathrm{H}), 2.96(\mathrm{~m}, 1 \mathrm{H}), 3.25(\mathrm{dd}, 1 \mathrm{H}, J=7.7,10.6 \mathrm{~Hz}), 3.42(\mathrm{~s}$, $3 \mathrm{H}), 4.26(\mathrm{~d}, 1 \mathrm{H}, J=4.4 \mathrm{~Hz}), 4.32(\mathrm{t}, 1 \mathrm{H}, J=6.2 \mathrm{~Hz}), 4.70$ $(\mathrm{d}, 1 \mathrm{H}, J=6.6 \mathrm{~Hz}), 4.97$ (d, $1 \mathrm{H}, J=6.6 \mathrm{~Hz}), 5.87 \sim 5.94(\mathrm{~m}$, 2H), 6.09, $6.21(2 \mathrm{~m}$, each $1 \mathrm{H}) ;{ }^{13} \mathrm{C}$ NMR $\delta 13.8,44.0$, 53.2, 53.6, 54.9, 56.3, 76.7, 77.6, 86.0, 95.9, 124.7, 126.2, 137.7, 138.2; EIHRMS calcd for $\mathrm{C}_{14} \mathrm{H}_{20} \mathrm{O}_{4}\left(\mathrm{M}^{+}\right) \mathrm{m} / \mathrm{z}$ 252.1362, found 252.1366. Compound 9b was isolated as a colorless oil: TLC Rf 0.44 (EtOAc/hexane, $3: 2) ;[\alpha]_{\mathrm{D}}^{24.0}$ +64.3 (c 0.54, $\mathrm{CHCl}_{3}$ ); IR (neat) $2940 \mathrm{~cm}^{-1} ;{ }^{1} \mathrm{H}$ NMR $\delta$ $1.07(\mathrm{~d}, 3 \mathrm{H}, J=7.0 \mathrm{~Hz}), 2.67 \sim 2.87(\mathrm{~m}, 5 \mathrm{H}), 3.19 \sim 3.25(\mathrm{~m}$, $1 \mathrm{H}), 3.38(\mathrm{~s}, 3 \mathrm{H}), 4.23(\mathrm{~d}, 1 \mathrm{H}, J=4.4 \mathrm{~Hz}), 4.60(\mathrm{~d}, 1 \mathrm{H}$, $J=7.0 \mathrm{~Hz}), 4.61(\mathrm{t}, 1 \mathrm{H}, J=6.8 \mathrm{~Hz}), 4.76(\mathrm{~d}, 1 \mathrm{H}, J=7.0 \mathrm{~Hz})$, $5.86 \sim 5.93(\mathrm{~m}, 2 \mathrm{H}), 6.07,6.36(2 \mathrm{~m}$, each $1 \mathrm{H}) ;{ }^{13} \mathrm{C}$ NMR $\delta$ 13.8, 46.5, 52.6, 53.1, 55.8, 56.1, 76.4, 77.1, 85.5, 96.2, 124.8, 125.5, 137.5, 139.2; EIHRMS calcd for $\mathrm{C}_{14} \mathrm{H}_{20} \mathrm{O}_{4}$ $\left(\mathrm{M}^{+}\right) \mathrm{m} / z$ 252.1362, found 252.1359.

\section{Epoxy-ring Opening of 9a by Lithium TMS-acetylide. Preparation of 10}

The following reaction was carried out under Ar. To a cooled $\left(-78^{\circ} \mathrm{C}\right)$ stirred solution of trimethylsilylacetylene $(50 \mu 1,0.36 \mathrm{mmol})$ in THF $(1 \mathrm{ml})$ was added $n$-BuLi ( $2.67 \mathrm{M}$ in hexane, $0.14 \mathrm{ml}, 0.36 \mathrm{mmol})$. The solution was stirred at $-78^{\circ} \mathrm{C}$ for 10 minutes and a solution of 9a $(9.1 \mathrm{mg}, 36 \mu \mathrm{mol})$ in THF $(1.5 \mathrm{ml})$ was added. The mixture was stirred at $-78^{\circ} \mathrm{C}$ for 10 minutes and then $\mathrm{BF}_{3} \cdot \mathrm{Et}_{2} \mathrm{O}$ ( $45 \mu 1,0.36 \mathrm{mmol})$ was added. The mixture was stirred while gradually warmed to $-30^{\circ} \mathrm{C}$ over 5 hours. The mixture was quenched with saturated aqueous $\mathrm{NH}_{4} \mathrm{Cl}$ $(1 \mathrm{ml})$, diluted with saturated aqueous $\mathrm{NH}_{4} \mathrm{Cl}(10 \mathrm{ml})$, and extracted with $\mathrm{CH}_{2} \mathrm{Cl}_{2}(5 \mathrm{ml} \times 3)$. The combined extracts were dried and concentrated in vacuo. The residue was purified by column chromatography on silica gel (EtOAc/hexane, $1: 4)$ to provide $11.0 \mathrm{mg}(99 \%)$ of $\mathbf{1 0}$ as a colorless oil: TLC Rf 0.48 (EtOAc/hexane, $2: 3$ ); $[\alpha]_{\mathrm{D}}^{24.5}$ +8.8 (c 0.55, $\mathrm{CHCl}_{3}$ ); IR (neat) 3450, 2960, $2180 \mathrm{~cm}^{-} 1$; ${ }^{1} \mathrm{H}$ NMR $\delta 0.15(\mathrm{~s}, 9 \mathrm{H}), 1.14(\mathrm{~d}, 3 \mathrm{H}, J=7.0 \mathrm{~Hz}), 2.48 \sim$ $2.57(\mathrm{~m}, 2 \mathrm{H}), 2.74(\mathrm{~m}, 1 \mathrm{H}), 2.87(\mathrm{~m}, 1 \mathrm{H}), 3.25(\mathrm{brd}, 1 \mathrm{H}$, $J=5.9 \mathrm{~Hz}), 3.42(\mathrm{~s}, 3 \mathrm{H}), 3.78 \sim 3.81(\mathrm{~m}, 1 \mathrm{H}), 3.87(\mathrm{dd}, 1 \mathrm{H}$, $J=1.8,7.7 \mathrm{~Hz}), 4.27$ (dd, $1 \mathrm{H}, J=2.6,4.8 \mathrm{~Hz}), 4.65(\mathrm{t}, 1 \mathrm{H}$, $J=5.0 \mathrm{~Hz}), 4.73(\mathrm{~d}, 1 \mathrm{H}, J=7.0 \mathrm{~Hz}), 4.81(\mathrm{~d}, 1 \mathrm{H}, J=7.0 \mathrm{~Hz})$, $5.87 \sim 5.95(\mathrm{~m}, 2 \mathrm{H}), 6.12 \sim 6.26(\mathrm{~m}, 2 \mathrm{H}) ;{ }^{13} \mathrm{C}$ NMR $\delta$ $0.2 \times 3,13.8,25.3,50.1,55.3,56.0,71.4,78.0,78.1,85.4$, 87.6, 97.5, 103.3, 125.2, 125.4, 137.5, 138.3; EIHRMS calcd for $\mathrm{C}_{19} \mathrm{H}_{30} \mathrm{O}_{4} \mathrm{Si}\left(\mathrm{M}^{+}\right) \mathrm{m} / z$ 350.1913, found 350.1924.

\section{$\gamma$-Lactone Formation. Preparation of 11}

To a stirred solution of $\mathbf{1 0}(11.0 \mathrm{mg}, 31.4 \mu \mathrm{mol})$ in DMF containing $1 \%$ water $(1 \mathrm{ml})$ were added $\mathrm{PdCl}_{2}(\mathrm{MeCN})_{2}$ $(16 \mathrm{mM}$ solution in DMF containing $1 \%$ water, $0.1 \mathrm{ml}$, $1.6 \mu \mathrm{mol})$ and $\mathrm{CuCl}_{2}(79 \mathrm{mM}$ solution in DMF containing $1 \%$ water, $0.1 \mathrm{ml}, 7.9 \mu \mathrm{mol}$ ). The mixture was stirred for 4 days and concentrated in vacuo. The residue was purified by column chromatography on silica gel (EtOAc/hexane, $2: 1)$ to provide $6.5 \mathrm{mg}(71 \%)$ of $\mathbf{1 1}$ as a colorless oil: TLC Rf 0.37 (EtOAc/hexane, 3:2); $[\alpha]_{\mathrm{D}}^{27.5}+16.9$ (c 0.33 , $\mathrm{CHCl}_{3}$ ); IR (neat) 2920, $1775 \mathrm{~cm}^{-1} ;{ }^{1} \mathrm{H}$ NMR $\delta 1.12(\mathrm{~d}$, $3 \mathrm{H}, J=7.0 \mathrm{~Hz}), 2.08 \sim 2.27(\mathrm{~m}, 2 \mathrm{H}), 2.54 \sim 2.61(\mathrm{~m}, 2 \mathrm{H})$, $2.65 \sim 2.81(\mathrm{~m}, 2 \mathrm{H}), 3.40(\mathrm{~s}, 3 \mathrm{H}), 3.82(\mathrm{dd}, 1 \mathrm{H}, J=4.4$, $8.8 \mathrm{~Hz}), 4.23(\mathrm{~d}, 1 \mathrm{H}, J=4.4 \mathrm{~Hz}), 4.52(\mathrm{t}, 1 \mathrm{H}, J=6.0 \mathrm{~Hz})$, $4.73(\mathrm{~m}, 1 \mathrm{H}), 4.75(\mathrm{~s}, 2 \mathrm{H}), 5.87 \sim 5.94(\mathrm{~m}, 2 \mathrm{H}), 6.06,6.26$ (2m, each $1 \mathrm{H}) ;{ }^{13} \mathrm{C}$ NMR $\delta 14.7,23.7,28.5,50.8,53.4$, 56.3, 77.2, 79.0, 80.8, 85.9, 97.9, 124.8, 125.9, 137.3, 138.6, 176.7; EIHRMS calcd for $\mathrm{C}_{16} \mathrm{H}_{22} \mathrm{O}_{5}\left(\mathrm{M}^{+}\right) \mathrm{m} / \mathrm{z}$ 294.1467, found 294.1478.

\section{B (2)}

Compound 11 ( $6.5 \mathrm{mg}, 22 \mu \mathrm{mol})$ was dissolved in $2 \mathrm{M}$ aqueous $\mathrm{HCl} / \mathrm{THF}(1: 1, \mathrm{v} / \mathrm{v}, 1 \mathrm{ml})$. After being stirred at $50^{\circ} \mathrm{C}$ for 1.5 hours, the solution was diluted with $\mathrm{H}_{2} \mathrm{O}$ $(10 \mathrm{ml})$ and extracted with EtOAc $(5 \mathrm{ml} \times 3)$. The combined extracts were dried and concentrated in vacuo. The residue was purified by column chromatography on silica gel (EtOAc/hexane, $3: 1$ ) to provide $5.4 \mathrm{mg}(98 \%)$ of de- $O$ - 
MOM derivative as a colorless oil: TLC Rf 0.28 (EtOAc/hexane, $4: 1)$; $[\alpha]_{\mathrm{D}}^{26.0}+56.0\left(c 0.25, \mathrm{CHCl}_{3}\right)$; IR (neat) $3450,2930,1775 \mathrm{~cm}^{-1}$; ${ }^{1} \mathrm{H}$ NMR $\delta 1.15(\mathrm{~d}, 3 \mathrm{H}$, $J=6.6 \mathrm{~Hz}$ ), 2.17 (br s, 1H), 2.26 2.47 (m, 2H), $2.53 \sim 2.65$ $(\mathrm{m}, 2 \mathrm{H}), 2.70 \sim 2.83(\mathrm{~m}, 2 \mathrm{H}), 3.58(\mathrm{~m}, 1 \mathrm{H}), 4.28(\mathrm{~d}, 1 \mathrm{H}, J$ $=4.8 \mathrm{~Hz}), 4.32(\mathrm{t}, 1 \mathrm{H}, J=5.7 \mathrm{~Hz}), 4.42(\mathrm{dt}, 1 \mathrm{H}, J=1.5$, $7.3 \mathrm{~Hz}), 5.88 \sim 5.95(\mathrm{~m}, 2 \mathrm{H}), 6.05,6.23(2 \mathrm{~m}$, each $1 \mathrm{H}) ;{ }^{13} \mathrm{C}$ NMR $\delta$ 14.1, 24.2, 28.6, 53.0, 54.4, 72.0, 76.8, 81.9, 86.5, $124.8,126.4,137.1,137.4,169.6$; EIHRMS calcd for $\mathrm{C}_{14} \mathrm{H}_{18} \mathrm{O}_{4}\left(\mathrm{M}^{+}\right) \mathrm{m} / z$ 250.1205, found 250.1203.

To a stirred solution of thus obtained compound (5.4 mg, $22 \mu \mathrm{mol})$ in pyridine $/ \mathrm{Ac}_{2} \mathrm{O}(1: 1, \mathrm{v} / \mathrm{v}, 1 \mathrm{ml})$ was added 4-DMAP $(1.3 \mathrm{mg}, 11 \mu \mathrm{mol})$. After being stirred for 30 minutes, the solution was concentrated in vacuo. The residue was purified by column chromatography on silica gel (EtOAc/hexane, $2: 1)$ to provide $5.3 \mathrm{mg}(84 \%)$ of 2 as colorless crystals: $\mathrm{mp} 138.5 \sim 140.7^{\circ} \mathrm{C}$; TLC Rf 0.48 (EtOAc/hexane, $4: 1) ;[\alpha]_{\mathrm{D}}^{27.4}+10.8$ (c 0.25 , acetone); IR (neat) $2920,1775,1730 \mathrm{~cm}^{-1} ;{ }^{1} \mathrm{H}$ NMR $\delta 0.98(\mathrm{~d}, 3 \mathrm{H}$, $J=7.0 \mathrm{~Hz}), 2.00 \sim 2.36(\mathrm{~m}, 2 \mathrm{H}), 2.11(\mathrm{~s}, 3 \mathrm{H}), 2.43 \sim 2.55$ (m, 2H), $2.72(\mathrm{~m}, 1 \mathrm{H}), 2.98$ (td, $1 \mathrm{H}, J=6.5,10.3 \mathrm{~Hz}), 4.24$ (d, $1 \mathrm{H}, J=4.4 \mathrm{~Hz}), 4.42$ (t, $1 \mathrm{H}, J=5.9,5.9 \mathrm{~Hz}), 4.57$ (ddd, 1 $\mathrm{H}, J=2.5,6.5,7.6 \mathrm{~Hz}), 5.15(\mathrm{dd}, 1 \mathrm{H}, J=2.4,10.4 \mathrm{~Hz}), 5.91$ $(\mathrm{m}, 1 \mathrm{H}), 5.95(\mathrm{~m}, 1 \mathrm{H}), 6.04(\mathrm{~m}, 1 \mathrm{H}), 6.24(\mathrm{~m}, 1 \mathrm{H}) ;{ }^{13} \mathrm{C}$ NMR $\delta 14.4,21.0,23.9,28.0,51.5,52.3,72.6,76.7,80.1$, 86.2, 125.0, 126.3, 136.9, 137.5, 170.5, 176.2; EIHRMS calcd for $\mathrm{C}_{16} \mathrm{H}_{20} \mathrm{O}_{5}\left(\mathrm{M}^{+}\right) \mathrm{m} / \mathrm{z} 292.1311$, found 292.1316.

\section{Preparation of 12}

Compound 9b was converted to $\mathbf{1 2}$ analogously as the conversion of $\mathbf{9 a}$ to $\mathbf{1 0}$. Compound $\mathbf{1 2}$ as a coloress oil: TLC Rf 0.60 (EtOAc/hexane, 2:3); $[\alpha]_{\mathrm{D}}^{25.0}+45.8$ (c 2.41, $\mathrm{CHCl}_{3}$ ); IR (neat) $3450,2950,2180 \mathrm{~cm}^{-1} ;{ }^{1} \mathrm{H}$ NMR $\delta 0.16$ (s, 9H), 1.04 (d, 3H, J=7.3 Hz), 2.31 2.53 (2m, 3H), 2.78 (m, 1H), 3.44 (s, 3H), 3.59 (m, 1H), 3.68 (dd, $1 \mathrm{H}, J=1.7$, $10.8 \mathrm{~Hz}), 4.25$ (d, 1H, J=4.4 Hz), 4.34 (t, $1 \mathrm{H}, J=6.0 \mathrm{~Hz}$ ), 4.69 (d, $1 \mathrm{H}, J=7.0 \mathrm{~Hz}), 4.78$ (d, $1 \mathrm{H}, J=7.0 \mathrm{~Hz}), 5.86 \sim 5.97$ $(\mathrm{m}, 2 \mathrm{H}), 6.06,6.26(2 \mathrm{~m}$, each $1 \mathrm{H}) ;{ }^{13} \mathrm{C}$ NMR $\delta 0.1 \times 3$, 14.0, 22.8, 52.8, 53.0, 56.1, 72.8, 76.7, 84.1, 86.1, 98.5, 103.9, 124.66, 126.31, 137.5, 137.9; EIHRMS calcd for $\mathrm{C}_{19} \mathrm{H}_{30} \mathrm{O}_{4} \mathrm{Si}\left(\mathrm{M}^{+}\right) \mathrm{m} / \mathrm{z} 350.1913$, found 350.1903 .

\section{Preparation of 13}

Compound $\mathbf{1 2}$ was converted to $\mathbf{1 3}$ analogously as the conversion of $\mathbf{1 0}$ to $\mathbf{1 1}$. Compound $\mathbf{1 3}$ as a coloress oil: TLC Rf 0.50 (EtOAc/hexane, $3: 2$ ); $[\alpha]_{\mathrm{D}}^{24.5}+46.2$ (c 1.0, $\mathrm{CHCl}_{3}$ ); IR (neat) $2940,1775 \mathrm{~cm}^{-1} ;{ }^{1} \mathrm{H}$ NMR $\delta 1.13(\mathrm{~d}$, $3 \mathrm{H}, J=7.3 \mathrm{~Hz}), 2.04 \sim 2.59(\mathrm{~m}, 5 \mathrm{H}), 2.81(\mathrm{~m}, 1 \mathrm{H}), 3.36(\mathrm{~s}$, $3 \mathrm{H}), 3.94$ (dd, $1 \mathrm{H}, J=1.7,9.9 \mathrm{~Hz}), 4.25(\mathrm{~d}, 1 \mathrm{H}, J=4.3 \mathrm{~Hz}$ ), 4.35 (t, 1H, $J=5.8 \mathrm{~Hz}), 4.46(\mathrm{dt}, 1 \mathrm{H}, J=1.7,7.5 \mathrm{~Hz}), 4.65$ $(\mathrm{d}, 1 \mathrm{H}), 4.76(\mathrm{~d}, 1 \mathrm{H}), 5.87 \sim 5.95(\mathrm{~m}, 2 \mathrm{H}), 6.09 \sim 6.20(2 \mathrm{~m}$,
$2 \mathrm{H}) ;{ }^{13} \mathrm{C}$ NMR $\delta 13.5,20.7,28.5,52.0,53.0,56.0,76.5$, 77.2, 82.5, 85.7, 98.0, 124.8, 126.5, 137.4, 138.0, 176.9; EIHRMS calcd for $\mathrm{C}_{16} \mathrm{H}_{22} \mathrm{O}_{5}\left(\mathrm{M}^{+}\right) \mathrm{m} / z$ 294.1467, found 294.1463.

\section{Preparation of 4-epi-1893B (14)}

Compound $\mathbf{1 3}$ was converted to $\mathbf{1 4}$ analogously as the conversion of $\mathbf{1 1}$ to $\mathbf{2}$. Compound $\mathbf{1 4}$ as a coloress oil: TLC Rf 0.56 (EtOAc/hexane, 2:1); $[\alpha]_{\mathrm{D}}^{25.2}+121.3$ (c 0.05 , acetone); IR (neat) 2950, 1775, $1750 \mathrm{~cm}^{-1}$; ${ }^{1} \mathrm{H}$ NMR $\delta 1.04$ (d, $3 \mathrm{H}, J=7.0 \mathrm{~Hz}), 2.08(\mathrm{~s}, 3 \mathrm{H}), 2.13 \sim 2.23(\mathrm{~m}, 2 \mathrm{H})$, $2.48 \sim 2.55(\mathrm{~m}, 2 \mathrm{H}), 2.65 \sim 2.78(\mathrm{~m}, 2 \mathrm{H}), 4.24(\mathrm{~d}, 1 \mathrm{H}$, $J=4.8 \mathrm{~Hz}), 4.43 \sim 4.50(\mathrm{~m}, 2 \mathrm{H}), 5.31(\mathrm{dd}, 1 \mathrm{H}, J=4.8$, $9.5 \mathrm{~Hz}), 5.88 \sim 5.97(\mathrm{~m}, 2 \mathrm{H}), 6.10,6.26(\mathrm{~m}$, each $1 \mathrm{H}) ;{ }^{13} \mathrm{C}$ NMR $\delta 14.3,20.9,22.9,28.1,52.4 \times 2,71.5,77.2,80.6$, 85.6, 124.9, 126.4, 137.6, 137.8, 169.6, 176.0; EIHRMS calcd for $\mathrm{C}_{16} \mathrm{H}_{20} \mathrm{O}_{5}\left(\mathrm{M}^{+}\right) \mathrm{m} / \mathrm{z} 292.1311$, found 292.1305.

\section{Preparation of $15 a$ and $15 b$}

Compound 6a was converted to $15 \mathbf{a}$ and $15 \mathbf{b}$ by $\mathrm{VO}(\mathrm{acac})_{2}-$ catalyzed epoxidation followed by MOM etherification. The ant-15a and syn-epoxy alcohols $\mathbf{1 5 b}$ were separated by chromatography on silica gel. Compound $\mathbf{1 5 a}$ was isolated as a coloress oil: TLC Rf 0.57 (EtOAc/hexane, $2: 3) ;[\alpha]_{\mathrm{D}}^{24.5}$ +101.8 (c 2.0, $\mathrm{CHCl}_{3}$ ); IR (neat) $2930 \mathrm{~cm}^{-1} ;{ }^{1} \mathrm{H}$ NMR $\delta$ 1.09 (d, 3H, $J=7.0 \mathrm{~Hz}), 2.61 \sim 2.80$ (m, 4H, H-8), 2.91 (m, $1 \mathrm{H}), 3.41(\mathrm{~s}, 3 \mathrm{H}), 3.58(\mathrm{dd}, 1 \mathrm{H}, J=4.8,9.9 \mathrm{~Hz}), 4.28(\mathrm{~d}$, $1 \mathrm{H}, J=4.4 \mathrm{~Hz}), 4.56(\mathrm{~d}, 1 \mathrm{H}), 4.64(\mathrm{t}, 1 \mathrm{H}, J=5.9 \mathrm{~Hz}), 4.77$ (d, 1H), 5.83 5.93 (m, 2H), 6.04, $6.29(2 \mathrm{~m}$, each $1 \mathrm{H}) ;{ }^{13} \mathrm{C}$ NMR $\delta$ 15.1, 44.7, 52.5, 53.1, 54.7, 56.0, 75.5, 78.9, 86.9, 96.7, 124.9×2, 137.1, 139.8; EIHRMS calcd for $\mathrm{C}_{14} \mathrm{H}_{20} \mathrm{O}_{4}$ $\left(\mathrm{M}^{+}\right) \mathrm{m} / z$ 252.1362, found 252.1358. Compound 15b was isolated as a colorless oil: TLC Rf 0.59 (EtOAc/hexane, $2: 3) ;[\alpha]_{\mathrm{D}}^{24.5}+70.0\left(c 0.45, \mathrm{CHCl}_{3}\right)$; IR (neat) $2940 \mathrm{~cm}^{-1}$; ${ }^{1} \mathrm{H}$ NMR $\delta 1.08(\mathrm{~d}, 3 \mathrm{H}), 2.63 \sim 2.81(\mathrm{~m}, 4 \mathrm{H}), 3.00(\mathrm{~m}, 1 \mathrm{H})$, 3.44 (s, 3H), 3.57 (dd, 1H, J=5.9, $9.2 \mathrm{~Hz}), 4.27$ (d, $1 \mathrm{H}$, $J=4.4 \mathrm{~Hz}), 4.64(\mathrm{~d}, 1 \mathrm{H}, J=6.6 \mathrm{~Hz}), 4.64(\mathrm{t}, 1 \mathrm{H}), 4.89(\mathrm{~d}$, $1 \mathrm{H}), 5.83 \sim 5.94(\mathrm{~m}, 2 \mathrm{H}), 6.04,6.29(2 \mathrm{~m}$, each $1 \mathrm{H}) ;{ }^{13} \mathrm{C}$ NMR $\delta 15.4,44.4,52.1,53.4,53.9,56.3,76.4,78.8,86.8$, 96.3, 125.0×2, 137.0, 139.7; EIHRMS calcd for $\mathrm{C}_{14} \mathrm{H}_{20} \mathrm{O}_{4}$ $\left(\mathrm{M}^{+}\right) \mathrm{m} / z$ 252.1362, found 252.1374.

\section{Preparation of 16}

Compound 15a was converted to $\mathbf{1 6}$ analogously as the conversion of 9a to $\mathbf{1 0}$. Compound $\mathbf{1 6}$ was isolated as a coloress oil: TLC Rf 0.61 (EtOAc/hexane, 2:3); $[\alpha]_{\mathrm{D}}^{25.0}$ +34.8 (c 2.19, $\mathrm{CHCl}_{3}$ ); IR (neat) 3440, 2960, $2190 \mathrm{~cm}^{-1}$; ${ }^{1} \mathrm{H}$ NMR $\delta 0.15$ (s, 9H), 1.08 (d, 3H, $\left.J=6.6 \mathrm{~Hz}\right), 2.42$ (dd, $1 \mathrm{H}, J=7.3,17.2 \mathrm{~Hz}), 2.53(\mathrm{dd}, 1 \mathrm{H}, J=5.5,17.2 \mathrm{~Hz}$ ), $2.64 \sim 2.70(\mathrm{~m}, 2 \mathrm{H}), 3,45(\mathrm{~s}, 3 \mathrm{H}), 3.56 \sim 3.74(\mathrm{~m}, 3 \mathrm{H}), 4.26$ $(\mathrm{d}, J=4.8 \mathrm{~Hz}), 4.49(\mathrm{t}, 1 \mathrm{H}, J=5.5 \mathrm{~Hz}), 4.68(\mathrm{~d}, 1 \mathrm{H}$, 
$J=7.0 \mathrm{~Hz}), 4.83(\mathrm{~d}, 1 \mathrm{H}, J=7.0 \mathrm{~Hz}), 5.80 \sim 5.91(\mathrm{~m}, 2 \mathrm{H})$, 6.01, $6.25(\mathrm{~m}$, each $1 \mathrm{H}) ;{ }^{13} \mathrm{C}$ NMR $\delta 0.1 \times 3,14.5,23.2$, 52.2, 52.8, 56.2, 71.2, 79.7, 85.5, 86.5, 86.9, 98.7, 103.8, 124.7, 125.0, 136.8, 139.8; EIHRMS calcd for $\mathrm{C}_{19} \mathrm{H}_{30} \mathrm{O}_{4} \mathrm{Si}$ $\left(\mathrm{M}^{+}\right) \mathrm{m} / \mathrm{z} 350.1913$, found 350.1921 .

\section{Preparation of 17}

Compound $\mathbf{1 6}$ was converted to $\mathbf{1 7}$ analogously as the conversion of $\mathbf{1 0}$ to $\mathbf{1 1}$. Compound $\mathbf{1 7}$ as a coloress oil: TLC Rf 0.27 (EtOAc/hexane, $3: 2) ;[\alpha]_{\mathrm{D}}^{23.5}+65.7$ (c 0.67, $\mathrm{CHCl}_{3}$ ); IR (neat) 2950, $1775 \mathrm{~cm}^{-1} ;{ }^{1} \mathrm{H}$ NMR $\delta 1.09$ (d, $3 \mathrm{H}, J=6.6 \mathrm{~Hz}), 2.07 \sim 2.58(\mathrm{~m}, 6 \mathrm{H}), 3.43(\mathrm{~s}, 3 \mathrm{H}), 3.97$ (dd, $1 \mathrm{H}, J=1.7,10.8 \mathrm{~Hz}), 4.28(\mathrm{~d}, 1 \mathrm{H}, J=4.4 \mathrm{~Hz}), 4.53(\mathrm{dt}, 1 \mathrm{H}$, $J=1.7,7.5 \mathrm{~Hz}), 4.63(\mathrm{~d}, 1 \mathrm{H}, J=6.6 \mathrm{~Hz}), 4.69(\mathrm{t}, 1 \mathrm{H}$, $J=5.9 \mathrm{~Hz}), 4.81(\mathrm{~d}, 1 \mathrm{H}, J=6.6 \mathrm{~Hz}), 5.83 \sim 5.93(\mathrm{~m}, 2 \mathrm{H})$, 6.01, 6.31 (2m, each $1 \mathrm{H}) ;{ }^{13} \mathrm{C}$ NMR $\delta 14.7,20.8,28.3$, $51.7,52.0,56.5,78.4,79.1,81.2,86.8,98.7,125.0,125.1$, 136.7, 139.8, 176.8; EIHRMS calcd for $\mathrm{C}_{16} \mathrm{H}_{22} \mathrm{O}_{5}\left(\mathrm{M}^{+}\right) \mathrm{m} / \mathrm{z}$ 294.1467, found 294.1474.

\section{Preparation of 5-epi-1893B (18)}

Compound $\mathbf{1 7}$ was converted to $\mathbf{1 8}$ analogously as the conversion of $\mathbf{1 1}$ to $\mathbf{2}$. Compound $\mathbf{1 8}$ as a coloress oil: TLC Rf $0.50\left(\right.$ EtOAc/hexane, 3:1) $[\alpha]_{\mathrm{D}}^{23.0}+44.3$ (c 0.50 , acetone); IR (neat) 2950, 1775, $1740 \mathrm{~cm}^{-1}$; ${ }^{1} \mathrm{H}$ NMR $\delta 1.08$ (d, 3H, J=6.6 Hz), $2.10(\mathrm{~s}, 3 \mathrm{H}), 2.12 \sim 2.36(\mathrm{~m}, 2 \mathrm{H})$, $2.48 \sim 2.56(\mathrm{~m}, 2 \mathrm{H}), 2.64 \sim 2.73(\mathrm{~m}, 2 \mathrm{H}), 4.26(\mathrm{~d}, 1 \mathrm{H}$, $J=4.4 \mathrm{~Hz}), 4.50$ (ddd, $1 \mathrm{H}, J=4.4,7.2,7.3 \mathrm{~Hz}), 4.64(\mathrm{t}, 1 \mathrm{H}$, $J=5.7 \mathrm{~Hz}), 5.30(\mathrm{dd}, 1 \mathrm{H}, J=4.0,7.2 \mathrm{~Hz}), 5.84 \sim 5.94(\mathrm{~m}$, 2H), $6.04(\mathrm{~m}, 1 \mathrm{H}), 6.22(\mathrm{~m}, 1 \mathrm{H}) ;{ }^{13} \mathrm{C}$ NMR $\delta 14.7,21.1$, 22.9, 28.0, 51.1, 53.1, 72.3, 77.4, 80.0, 86.2, 124.9, 125.4, 137.0, 138.8, 169.9, 176.1; EIHRMS calcd for $\mathrm{C}_{16} \mathrm{H}_{20} \mathrm{O}_{5}$ $\left(\mathrm{M}^{+}\right) \mathrm{m} / z$ 292.1311, found 292.1315.

\section{Preparation of 19}

Compound $\mathbf{1 5 b}$ was converted to 19 analogously as the conversion of 9a to $\mathbf{1 0}$. Compound $\mathbf{1 9}$ as a coloress oil: TLC Rf 0.48 (EtOAc/hexane, 2:3); $[\alpha]_{\mathrm{D}}^{22.0}+47.6$ (c 0.77, $\mathrm{CHCl}_{3}$ ); IR (neat) $3400,2960,2190 \mathrm{~cm}^{-1} ;{ }^{1} \mathrm{H}$ NMR $\delta 0.20$ (s, 9H), 1.09 (d, 3H, J=7.0 Hz), 2.38 2.77 (m, 3H), 2.93 (m, $1 \mathrm{H}), 3.46(\mathrm{~s}, 3 \mathrm{H}), 3.90(\mathrm{~d}, 1 \mathrm{H}, J=9.9 \mathrm{~Hz}), 4.26(\mathrm{~d}, 1 \mathrm{H}$, $J=4.0 \mathrm{~Hz}), 4.52(\mathrm{~m}, 1 \mathrm{H}), 4.67(\mathrm{t}, 1 \mathrm{H}, J=6.2 \mathrm{~Hz}), 4.73(\mathrm{~d}$, $1 \mathrm{H}), 4.83(\mathrm{~d}, 1 \mathrm{H}, J=6.6 \mathrm{~Hz}), 5.87 \sim 5.92(\mathrm{~m}, 2 \mathrm{H}), 6.02$, $6.28(\mathrm{~m}$, each $1 \mathrm{H}) ;{ }^{13} \mathrm{C}$ NMR $\delta-0.1 \times 3,14.6,25.9,52.1$, $52.3,56.5,70.6,78.9,80.3,86.8 \times 2,98.6,102.5,124.9$, 125.1, 137.0, 139.6; EIHRMS calcd for $\mathrm{C}_{19} \mathrm{H}_{30} \mathrm{O}_{4} \mathrm{Si}\left(\mathrm{M}^{+}\right)$ $\mathrm{m} / \mathrm{z} 350.1913$, found 350.1931 .

\section{Preparation of 20}

Compound 19 was converted to 20 analogously as the conversion of $\mathbf{1 0}$ to $\mathbf{1 1}$. Compound $\mathbf{2 0}$ as a coloress oil:
TLC Rf 0.53 (EtOAc/hexane, $4: 1) ;[\alpha]_{\mathrm{D}}^{20.5}+22.5(c 0.25$, $\mathrm{CHCl}_{3}$ ); IR (neat) 2940, $1775 \mathrm{~cm}^{-1} ;{ }^{1} \mathrm{H}$ NMR $\delta 1.07(\mathrm{~d}$, $3 \mathrm{H}, J=7.0 \mathrm{~Hz}), 2.17 \sim 2.28(\mathrm{~m}, 2 \mathrm{H}), 2.46 \sim 2.69(\mathrm{~m}, 3 \mathrm{H})$, $2.83(\mathrm{~m}, 1 \mathrm{H}), 3.43(\mathrm{~s}, 3 \mathrm{H}), 3.71(\mathrm{dd}, 1 \mathrm{H}, J=3.1,9.7 \mathrm{~Hz})$, 4.26 (d, $1 \mathrm{H}, J=4.4 \mathrm{~Hz}), 4.58$ (dt, $1 \mathrm{H}, J=3.2,7.3 \mathrm{~Hz}), 4.62$ $(\mathrm{t}, 1 \mathrm{H}, J=5.9 \mathrm{~Hz}), 4.75(\mathrm{~d}, 1 \mathrm{H}, J=3.7 \mathrm{~Hz}), 4.77(\mathrm{~d}, 1 \mathrm{H}$, $J=3.7 \mathrm{~Hz}), 5.83 \sim 5.93(\mathrm{~m}, 2 \mathrm{H}), 6.03,6.25(2 \mathrm{~m}$, each $1 \mathrm{H})$; ${ }^{13} \mathrm{C}$ NMR $\delta 14.9,23.4,28.3,52.1 \times 2,56.6,78.5,79.7$, 80.4, 86.7, 98.4, 125.2×2, 136.9, 139.3, 176.9; EIHRMS calcd for $\mathrm{C}_{16} \mathrm{H}_{22} \mathrm{O}_{5}\left(\mathrm{M}^{+}\right) \mathrm{m} / \mathrm{z} 294.1467$, found 294.1455.

\section{Preparation of 4,5-di-epi-1893B (21)}

Compound $\mathbf{2 0}$ was converted to $\mathbf{2 1}$ analogously as the conversion of $\mathbf{1 1}$ to $\mathbf{2}$. Compound $\mathbf{2 1}$ as a coloress oil: TLC Rf 0.41 (EtOAc/hexane, 4:1) $[\alpha]_{\mathrm{D}}^{23.5}+1.5$ (c 0.31 , acetone); IR (neat) 2940, 1775, $1740 \mathrm{~cm}^{-1} ;{ }^{1} \mathrm{H}$ NMR $\delta 1.07$ $(\mathrm{d}, 3 \mathrm{H}, J=7.0 \mathrm{~Hz}), 2.13(\mathrm{~s}, 3 \mathrm{H}), 2.24 \sim 2.36(\mathrm{~m}, 2 \mathrm{H})$, $2.46 \sim 2.58(\mathrm{~m}, 2 \mathrm{H}), 2.78(\mathrm{~m}, 1 \mathrm{H}), 2.94(\mathrm{~m}, 1 \mathrm{H}), 4.25(\mathrm{~d}$, $1 \mathrm{H}, J=4.4 \mathrm{~Hz}), 4.49$ (t, $1 \mathrm{H}, J=6.0 \mathrm{~Hz}), 4.56(\mathrm{~m}, 1 \mathrm{H}), 5.21$ (dd, $1 \mathrm{H}, J=2.6,8.8 \mathrm{~Hz}), 5.85 \sim 5.94(\mathrm{~m}, 2 \mathrm{H}), 6.03(\mathrm{~m}, 1 \mathrm{H})$, $6.17(\mathrm{~m}, 1 \mathrm{H}) ;{ }^{13} \mathrm{C}$ NMR $\delta 14.7,23.9,28.0 \times 2,51.4,52.4$, 73.2, 77.9, 79.6, 86.5, 125.1, 125.6, 136.8, 138.5, 172.8, 176.1; EIHRMS calcd for $\mathrm{C}_{16} \mathrm{H}_{20} \mathrm{O}_{5}\left(\mathrm{M}^{+}\right) \mathrm{m} / z$ 292.1311, found 292.1313 .

Acknowledgement This work was supported by Grant-in-Aid for the 21st Century COE program "KEIO Life Conjugate Chemistry" from MEXT, Japan. We thank Infectious Disease Research Labs., Meiji Seika Kaisha, Ltd., for performing the biological assays. We thank Professors Yongcheng Lin (Zhongshan University) and Guangying Chen (City University of Hong Kong) for providing spectral data of the natural product.

\section{References}

1. Chen G, Lin Y, Wen L, Vrijmoed LLP, Jones EBG. Two new metabolites fungus (No. 1893) from an estuarine mangrove on the South China Sea coast. Tetrahedron 59: 4907-4909 (2003)

2. Cai P, McPhail AT, Krainer E, Katz B, Pearce C, Boros C, Caseres B, Smith D, Houck DR. Mycoepoxydiene represents a novel class of fungal metabolites. Tetrahedron Lett 40: 1479-1482 (1999)

3. Lin X, Huang Y, Fang M, Wang J, Zheng Z, Su W. Cytotoxic and antimicrobial metabolites from marine lignicolous fungi, Diaporthe sp. FEMS Microbiology Lett 251: 53-58 (2005)

4. Takao K, Watanabe G, Yasui H, Tadano K. Total synthesis of ( \pm )-mycoepoxydiene, a novel fungal metabolite having an oxygen-bridged cyclooctadiene skeleton. Org Lett 4: 2941-2943 (2002)

5. Takao K, Yasui H, Yamamoto S, Sasaki D, Kawasaki S, 
Watanabe G, Tadano K. Asymmetric total syntheses of (+)mycoepoxydiene and related natural product $(-)-1893 \mathrm{~A}$ : Application of one-pot ring-opening/cross/ring-closing metathesis to construct their 9-oxabicyclo[4.2.1]nona-2,4diene skeleton. J Org Chem 69: 8789-8795 (2004)

6. Yasui H, Hirai K, Yamamoto S, Takao K, Tadano K. Total synthesis of $(+)-1893 \mathrm{~B}$ aimed at establishing its stereochemistry. Heterocycles 67: 123-128 (2006)

7. Chataigner I, Lebreton J, Durand D, Guingant A, Villiéras J. A new approach for the determination of the absolute configuration of secondary alcohols by ${ }^{1} \mathrm{H}$ NMR with $\mathrm{O}$ substituted mandelate derivatives. Tetrahedron Lett 39:
1759-1762 (1998)

8. Rossiter BE, Verhoeven TR, Sharpless KB. Stereoselective epoxidation of acyclic allylic alcohols. A correction of our previous work. Tetrahedron Lett 20: 4733-4736 (1979)

9. Mitsunobu O. The use of diethyl azodicarboxylate and triphenylphosphine in synthesis and transformation of natural products. Synthesis 1981: 1-28 (1981)

10. Compain P, Goré J, Vatèle J-M. Palladium(11)-catalyzed formation of $\gamma$-butyrolactones from 4-trimethylsilyl-3alkyn-1-ols: Synthetic and mechanistic aspects. Tetrahedron 52: 10405-10416 (1996) 